\title{
EL FUTURO DE ESPAÑA DEPENDE DE LA CIENCIA
}

$\mathrm{L}$ a ciencia se está convirtiendo en la fuerza que empuja la economía y asegura la prosperidad de los países. Así fue reconocido por la Unión Europea en la cumbre de Lisboa del 2000 en la cual los jefes de Estado y de Gobierno concluyeron que Europa tenía que convertirse en líder mundial de la economía basada en el conocimiento para el año 2010 si quería mantener su competitividad. Más tarde, en la cumbre de Barcelona del 2002, los mismos mandatarios decidieron que la inversión en Investigación y Desarrollo (I+D) debería aumentar hasta el 3\% del Producto Interior Bruto (PIB) en el año 2010. Por el momento estas palabras no se han traducido en actuaciones tangibles, pero en los últimos meses hay algunos indicios de que nos movemos en la dirección correcta tanto en el ámbito español como europeo.

Hasta ahora la investigación no había estado presente en las campañas electorales de los partidos políticos españoles. En respuesta a una propuesta de Pacto de Estado por la Ciencia, presentada públicamente por la Sociedad Española de Bioquímica y Biología Molecular, la ciencia ha saltado a los titulares de los medios de comunicación en las últimas elecciones generales. Todos los partidos políticos importantes dieron soporte a esta iniciativa. El Sr. Rodríguez Zapatero, candidato del PSOE (Partido Socialista), prometió un incremento anual del $25 \%$ en I+D durante los cuatro años de su mandato. Este incremento podría catapultar la investigación científica en España y mejorar su posición en Europa. En este momento España invierte un $1 \%$ de su PIB en $\mathrm{I}+\mathrm{D}$, aunque esta partida incluye algunos gastos militares que muy difícilmente podrían considerarse I+D. En lo más alto del ranking europeo, Finlandia y Suecia invierten alrededor del $4 \%$. Para poder competir con ellos los españoles deberían ser cuatro veces más inteligentes o trabajar cuatro veces más. Ninguna de las dos alternativas parece razonable.

El 15 de marzo, un día después de las elecciones generales que cambiaron el escenario político español y dieron el poder al PSOE, se eligió el primer comité ejecutivo de la COSCE (Confederación de Sociedades Científicas de España) que tiene como objetivo agrupar a todas las sociedades genuinamente científicas, desde las ciencias sociales a las clínicas. La COSCE confía que el Sr. Rodríguez Zapatero cumplirá sus promesas; sin embargo, un aumento del presupuesto, aunque absolutamente necesario, no sería suficiente. Es imprescindible dotarse de un sistema de gestión de la I+D flexible y eficaz que sustituya a las anquilosadas estructuras actuales. Necesitamos un sistema basado en criterios científicos, gestionado por científicos e independiente de los vaivenes políticos.

A escala europea, la idea de crear un Consejo Europeo de Investigación está ganando adeptos. La misión de ese Consejo sería promover la excelencia como base del progreso social, cultural y tecnológico en Europa, financiando proyectos de investigación de alto nivel. Su gran reto es colocar a Europa en la primera línea de la investigación internacional. España debe tener en cuenta esta oportunidad y establecer unas estructuras que le permitan maximizar su participación en el sistema europeo.

En este sentido la COSCE actuará como grupo de presión para fomentar la investigación, mejorar la enseñanza de la ciencia, difundir el espíritu científico en la sociedad y promover la apreciación social por el valor de la ciencia. Estamos convencidos que nuestros líderes estaban en lo cierto cuando afirmaron que Europa tiene que convertirse en una economía basada en el conocimiento si no quiere perder su posición de privilegio. Para que ello ocurra la sociedad en su conjunto debe ser consciente del valor de la educación y de la ciencia como factores impulsores del crecimiento económico. Todos los agentes sociales deben tomar parte en esta revolución que decidirá el bienestar de los países en el siglo XXI. España debe contribuir al reto de hacer de Europa la economía más competitiva y dinámica del mundo para el año 2010. Los científicos estamos listos para llevar a cabo nuestra parte. Ahora es el turno de los políticos. Es el momento para que actúen y den a la investigación y a la educación la máxima prioridad política. Nuestros hijos se lo agradecerán.

JOAN J. GUINOVART*

Presidente de COSCE

* El Dr. J. Guinovart es Director del IRBB, Parque Científico de Barcelona, España, y miembro del Comité Editorial de BR. 